\title{
DEL DERECHO A LA CIENCIA DEL DERECHO
}

\section{Dr. Juan de Dios González Ibarra •}

La Facultad de Derecho de la UNAM empezó con el sistema de doctorado por investigación a partir del semestre 92-II, esta acertada modalidad había sido incorporada ya con anterioridad al Reglamento General de Estudios de Posgrado, con objeto de cumplir con el artículo 7o. que señala la finalidad de que los estudios del doctorado formen científicos para la investigación original. Esto significa que el grado académico de doctor lleva implícita la condición, de contar con los conocimientos y la formación en la metodología de la ciencia jurídica que permitan hacer avanzar las fronteras de nuestra ciencia social.

La moderna decisión tomada implicará una serie de cambios positivos profundos, no sólo en la División de Estudios de Posgrado sino en toda la Facultad de Derecho, pues la propia experiencia nos ha demostrado que el posgrado en una Facultad permite elevar el nivel de docencia e investigación en toda ella. El escenario en el que se presenta es el de una crisis de los posgrados nacionales, reciente apenas el debate nacional por la evaluación realizada por Conacyt hacia el posgrado en el que Miguel José Yacamán, director adjunto de ese organismo, afirmó que la mayoría eran sólo "posgrados de papel" por no cumplir con los requisitos mínimos del máximo nivel del grado universitario.

La resolución tomada significará un largo aprendizaje para toda la comunidad de jurisprudencia, en la cual tanto alumnos como maestros y tutores, nos veremos inmersos en una dinámica que despertará y desarrollará cualidades en la investigación y la docencia, preocupaciones científicas relacionadas con el derecho y su metodología, junto con inquietudes, resistencias y tensiones. Es un cambio que nos llevará

- Profesor de Politica Tributaria en la División de Estudios de Posgrado de Ia Facultad de Derecho de la UNAM. Profesor Investigador de la UAM Xochimilco, Investigador Nacional. SNI. 
como profesores de la seguridad de nuestras cátedras, que lo que buscan es la segura transmisión de los conocimientos acumulados ya sea por la humanidad o una nación en su devenir histórico, hacia alumnos que a nivel de licenciatura van al aula a adquirir los conocimientos básicos del Derecho, hacia nada seguras zonas entre las cuales hay que evitar la tentación de lo obvio.

El camino emprendido nos dirigirá de la confianza del dominio de una de las áreas del Derecho, hacia el límite de esa seguridad que implica el campo resbaladizo de las fronteras del conocimiento, que se delimita tan sólo cientificamente por los parámetros marcados por lo verdadero y lo falso, conforme el quehacer universal de la ciencia en cualquiera área del sistema científico.

Sé que el cambio no será fácil, lo he vivido en otras instituciones, despierta resistencias producto de nuestros propios sistemas en los que fuimos instruidos conforme cátedras, apuntes, manuales o la afirmación de que lo que el maestro dice es la verdad. Sin embargo, el camino de la investigación original no implica una continuación de la licenciatura, los objetivos tanto de las maestrías como los doctorados son diferentes, luego entonces, no estamos ante una continuidad sino ante una nueva dimensión en el proceso de enseñanza-aprendizaje, ante diferentes retos con dinámicas propias que implican otros desafíos y desarrollo de habilidades, aptitudes y actitudes relacionadas básicamente con la investigación científica y no la docencia (Camero-Francisco, 1989).

Lo anterior implica que por necesidad se tendrá que desarrollar una comunidad científica, con las requeridas características de comunicación "ningún grupo de investigadores, o campo de investigación, está completamente aislado de otros.

Los intercambios de ideas, las participaciones de individuos en dos o más grupos o campos, las publicaciones en revistas multidisciplinarias y los lazos organizacionales y sociales, permiten la difusión de las ideas en toda la comunidad... Las fronteras entre una y otra disciplinas son flexibles, y de continuo surgen campos híbridos en tanto el contexto de los hechos no pertenecen a una sola disciplina" (Liberman y Wolf, 1990), verificación rigurosa de resultados entre investigadores con lo cual, estoy cierto, vendrán aportaciones relevantes en el campo de la ciencia jurídica que harán avanzar las fronteras del conocimiento en este campo. 
La labor sustantiva universitaria de la enseñanza tiene en primera instancia por objeto formar profesionales, "sin embargo las fallas pedagógicas de los programas de formación afectan los vínculos de la investigación con la docencia y posibilitan el divorcio tácito entre investigación y prácticas profesionales" (Bojalil, 1988), el posgrado toma como objeto primario de estudio la realidad y permite la vinculación institucional universidad-comunidad en el campo de la investigación social.

En el posgrado hoy asistimos en la Facultad de Derecho, al nacimiento de la semilla de una comunidad cientifica que incorporará los valores de la rigurosidad de la metodología y la disputa por la ciencia, junto con el fortalecimiento de la docencia.

La confrontación que se presentará es la del derecho y la ciencia del derecho (Tamayo y Salmorán, R., 1986), en la cual nuestro objeto de preocupación es la segunda, en la que "la explicación cientifica es una transición del conocimiento de los hechos, al conocimiento de las causas de los hechos".

Señalaré, con el mejor de los ánimos, algunos retos que tendremos por delante;

1) La tolerancia y receptibilidad hacia los argumentos de los demás como base de la discusión cientffica, esto no es fácil, pues nos hemos formado en la ideología de la práctica forense en que lo importante no es el fondo sino la forma, que se debe vencer en el litigio en el cual el compromiso con nuestro cliente es un deber fundamental;

2) El estudio por materias en el cual cada especialista domina un aspecto particular del Derecho, sin que hayamos partidos muchas veces de la reflexión del Derecho como ciencia, sino que lo hemos considerado como "una ciencia integrada por normas juridicas cuyo cumplimiento vigila el Estado (Gutiérrez Aragón, R., 1975), presentándose una confusión entre el Derecho como un conjunto de normas de observancia obligatoria y la ciencia del Derecho que tiene por objeto propio de estudio - como lo tiene cualquier otra ciencia- el universo jurídico con sus objetos, sujetos, hechos, relaciones (Lara, Leoncio, 1991), con el propósito de descubrir las leyes de regularidad, causas, efectos y en general la racionalidad de los procesos jurídicos (Ovilla Mandujano, M., 1990).

3) Nuestra propia formación basada en la clase o cátedra en la cual el hablar y escuchar es la dinámica básica del proceso de enseñanzaaprendizaje, o sea es una cultura oral (Camero, F., 1989), cuando en el 
posgrado la comunicación idónea de los resultados de la investigación deben realizarse por escrito, para que puedan ser evaluados por colegas con igual capacidad o mayor que el que investiga, la búsqueda de la sustitución de los paradigmas científicos o modelos explicativos vigentes (Serrano A. Jorge, 1990);

4) La crítica como medio de superación de la investigación es algo incómodo porque se confunde con el ataque personal, no sólo en la universidad mexicana sino en la realidad nacional, estamos acostumbrados a que la crítica sea sinónimo de ataque y no, como lo es, una evaluación del objeto de estudio, la palabra criterio proviene de la misma raíz de ésta;

5) Vincular la investigación con la docencia es también otra de las tareas que se tendrán que desarrollar, la figura del profesor-investigador no se desarrolla por decreto, sino que exige todo un aprendizaje que choca contra nuestra propio autoimagen (Fortes y Lomnitz, 1991), en la cual valores que nos daban una gran seguridad delante de los alumnos se verán sustituidos por otros como originalidad, crítica, autocrítica, curiosidad cientffica, duda metódica, independencia de criterio, disciplina en la investigación, soledad como ingrediente del quehacer científico, la pertenencia a comunidades invisibles o redes invisibles (Liberman y Wolf, 1990) formadas por científicos de todo el mundo preocupados por la ciencia del Derecho;

6) Horizontalidad en la relación de los investigadores en formacióninvestigadores reconocidos, en la cual la autoridad del maestro se basa no en el nombramiento o en la formalidad del título, sino en su curriculum y principalmente en sus resultados como investigador;

7) El papel de tutor que guía y coordina las discusiones es muy diferente al de maestro, éste enseña como lo mencionamos lo que la ciencia dentro del paradigma o paradigmas científicos dominantes de su momento histórico considera como verdades "evidentes", los paradigmas considerados "como realizaciones científicas universalmente reconocidas que, durante cierto tiempo, proporcionan modelos de problemas y soluciones a una comunidad científica" (Khun, T., 1986), nos brindan la seguridad del manejo del conocimiento aceptado por la comunidad científica universal, mientras que el trabajar en los límites o fronteras del conocimiento provoca inseguridades, temores, frustraciones pero al mismo tiempo retos y satisfacciones provenientes de la originalidad creativa que permite el avance del conocimiento; 
8) La relación tutor-alumno se basa en el trabajo investigativo como individuo y grupo, los resultados se evalúan por lo producido y no por lo aprendido, la tarea es común, los retos y dificultades de cada investigación interesan a todos, los logros son asimilados no sólo de manera personal sino que gracias a la relación tutor-alumno-grupo se socializan y se consideran como propios, el problema del conocimiento científico es concebido no como de aprendizaje sino como obstáculo a vencer (Bachelard, 1983).

La discusión conviene que transite por la validez o no de las llamadas ciencias nomotéticas o sea aquellas que buscan establecer leyes y de las ciencias históricas, entre el carácter internalista del desarrollo científico y el externalista o sea el reconocimiento de que todo conocimiento cientifico es fatalmente un producto social (Saldaña, J., 1989). El conocimiento mismo es objeto de estudio y la relación entre éste y el sujeto cognoscente cobra vital importancia, la epistemología se convierte en una disciplina auxiliar del investigador y en un escenario necesario (Piaget, J., 1977), implica entrar al debate de la cientificidad de las ciencias del espíritu o sociales por oposición a las llamadas ciencias duras como la física, química o biologia, defender, con razón y pasión, ambas igualmente importantes, el que si las ciencias sociales no usen el método experimental (Serrano, 1990) de las llamadas "exactas", no significa que nuestro quehacer cientifico se base en el sentido común, por el contrario, podríamos afirmar que el acceso al conocimiento científico en las ciencias sociales tiene que enfrentarse a resistencias, intereses y barreras que en las ciencias "duras" no se presentan, lo heroico y el espíritu de sacrificio científico en nuestro campo social también tiene a sus mártires, así Galileo o Giordano Bruno son perseguidos ¿por sus descubrimientos en las ciencias exactas o por sus repercusiones en las ciencias humanas?, y en las quemas de libros por gobiernos autoritarios sería imposible determinar cuál ha ocupado el primer lugar.

En nuestro campo cuando lo jurídico deja de ser secreto de fórmulas sagradas de iniciados, empieza la posibilidad práctica de poder constituirse el objeto científico del derecho, y la humanidad contempla al derecho como un objeto de conocimiento y desarrollo.

La historia nos demuestra que el avance en las ciencias duras y en la tecnologia si no lleva al desarrollo de las llamadas por la UNESCO ciencias del hombre, sin el respeto de los derechos humanos, la justicia - la democracia, la ciencia se convierte en barbarie tecnificada como 
en el reciente caso de la plaza de Tiananmenn, que mostró los costos que implica el abismo entre ciencias exactas y tecnología contra ciencias del espíritu, las últimas noticias nos muestran que esto cambiará a corto plazo porque el sistema científico funciona como un todo inseparable;

9) La actualización incesante de los conocimientos sobre el Derecho se convierten en insumos indispensables para retroalimentar el trabajo científico, la interdisciplinariedad como forma de trabajar con especialistas en otras ciencias se vuelve necesaria, el pensar no en lo existente sino en lo posible y deseable (Koyré, 1984), permite avanzar entre terrenos desconocidos;

10) Pasar de la dinámica de las respuestas a las preguntas, en la licenciatura las respuestas corren a cargo del profesor mientras que las preguntas se mueven en el marco de lo conocido, en el posgrado la formulación de preguntas son la base de nuevas inquietudes, pues la ciencia avanza fundamentalmente a través de la capacidad del hombre de asombrarse y formular preguntas a ese motivo de asombro.

La primera universidad fue la de Bolonia de 1088, la UNAM encuentra sus origenes en cédula de Carlos V de 1551 y Bula Papal de Clemente VIII de 1555, leyes fue una de las cátedras con las que se iniciaron las Facultades Mayores está impartida por el fiscal de la Real Audiencia de la Ciudad en 1553, y nuestra Facultad ha engendrado o dado a luz distintas carreras como Ciencia Política, Trabajo Social, Sociología, Economía y Administración Pública.

Conforme los fines del Derecho consistentes en garantizar las condiciones que permitan a la sociedad lograr el bien común por medio de la justicia, el orden y la seguridad (Le Fur, 1944), el paso que acaba de dar la Facultad de Derecho servirá de seguro al país para obtener lo anterior, sin embargo el camino no será fácil ni se podrán evitar la presencia de obstáculos y resistencias. 